\title{
Restraint stress abates the antioxidant potential of melatonin on dimethyl benz (a) anthracene (DMBA) induced carcinogenesis
}

\author{
Irfana Muqbil ${ }^{1,2}$ - Sabiha Fatima ${ }^{3}$ Asfar S. Azmi ${ }^{4}$. Ashwag Saleh Alsharidah ${ }^{5}$ Shahida Aziz Khan ${ }^{6}$ Feda Aljaser $^{7}$. \\ Naheed Banu ${ }^{1,8}$ iD
}

Received: 5 August 2020 / Accepted: 15 September 2020 / Published online: 29 September 2020

○) Springer Science+Business Media, LLC, part of Springer Nature 2020

\begin{abstract}
Free radical involvement in initiation, promotion and progression of carcinogenesis, implicates that scavengers of free radicals may act as inhibitors in the carcinogenic process. Melatonin, an antioxidant was used in the present study to evaluate its effectiveness on skin carcinogenesis induced by DMBA both with and without chronic restraint stress (CRS). Fifty Swiss albino young male rats were divided into five groups of 10 rats each as controls, topical DMB alone, Pre CRS-DMBA, melatonin DMBA and Pre-CRS-DMBA-melatonin treated groups. After 18 weeks blood was collected along with liver and skin samples. These were used for antioxidant enzyme assay, DNA damage and fluorescent spectra analysis. Melatonin showed antioxidant potential in combatting DMBA induced skin carcinogenesis measured by free radical scavenging enzymes and in vivo antioxidant status, DNA damage. Sensitive detection of the DMBA induced micro biochemical changes was possible by fluorescent spectroscopy from the transformed ratio of fluorescent intensity (F1 $530 \mathrm{~nm} / 630 \mathrm{~nm})$ otherwise found constant for normal tissues. By melatonin treatment this ratio was similar to control values. The decreased antioxidant biochemical parameters depicting oxidative stress were comparable to comet assay and fluorescent studies, endorsing the chemo-preventive efficacy of melatonin against skin carcinogenesis caused by DMBA. CRS pre-exposure diminished the chemo-preventive/ antioxidant ability of melatonin and the results were same as DMBA alone treatment, showing stress affected both cancer development and chemoprevention. CRS decreased the antioxidant potential of melatonin. Hence, managing stress could be perceived in cancer chemoprevention. Further studies focusing on stress reduction are needed.
\end{abstract}

Keywords Restraint stress $\cdot$ Carcinogenesis $\cdot$ Melatonin $\cdot$ DMBA $\cdot$ Oxidative stress

Naheed Banu

nbanuamu@gmail.com; naheedbanu7@yahoo.com;

n.banu@qu.edu.sa

Irfana Muqbil

muqbilr@udmercy.edu

Sabiha Fatima

sabmehdi@ksu.edu.sa

Asfar S. Azmi

azmia@karmanos.org

Ashwag Saleh Alsharidah

ashriedt@qu.edu.sa

Shahida Aziz Khan

shahidakhan2009@gmail.com

Feda Aljaser

faljaser@ksu.edu.sa

1 Department of Biochemistry, Faculty of Life Sciences, AMU, Aligarh 202002, India

2 Department of Chemistry, University of Detroit Mercy, Detroit, MI 48221, USA
3 Department of Clinical Laboratory Sciences, College of Applied Medical Sciences, King Saud University, P.O. Box 10219, Riyadh 11433, Kingdom of Saudi Arabia

4 Department of Oncology, Karmanos Cancer Institute, Wayne State University School of Medicine, Detroit, MI 48201, USA

5 Department of Physiology, College of Medicine, Qassim University, Buraidah, Qassim, Kingdom of Saudi Arabia

6 Applied Nutrition Group, King Fahd Medical Research Center, Department of Medical Laboratory Technology, Faculty of Applied Medical Sciences, King Abdulaziz University, Jeddah, Kingdom of Saudi Arabia

7 Chair-Medical and Molecular Genetics Research, Department of Clinical Laboratory Sciences, College of Applied Medical Sciences, King Saud University, Riyadh 11433, Kingdom of Saudi Arabia

8 Present Address: Department of Physical Therapy, College of Medical Rehabilitation, Qassim University, P.O.Box 51451, Buraidah, Qassim, Kingdom of Saudi Arabia 


\section{Introduction}

Cancer is only next to cardiovascular diseases causing mortality in the developed world [1]. The influence of oxidative stress during the induction, and progression of cancer; as well as its involvement in its molecular mechanisms is evident from earlier researches [2, 3]. Therefore greater emphasis has been laid down on cancer chemoprevention by antioxidants and free radical scavengers. Recent studies focusing on the anti-cancer properties of the pineal indole hormone melatonin ( $\mathrm{N}$-acetyl-5-methoxytryptamine) are being done, which is found to be a more potent and effective scavenger of free radicals as compared to other known antioxidants $[4,5]$. Melatonin as an antioxidant can protect cells directly [6] and also indirectly through activation of antioxidant enzymes which is receptor mediated [4]. Though melatonin has been found to inhibit spontaneous and chemically induced carcinogenesis [6], the person's response to chemotherapy decides the preventative action.

Stressful events alter the in vivo antioxidant status in particular and melatonin is effective as a potent antioxidant both in vitro, and in vivo [7]. Past researches advocate that stress is crucial and the ability to manage it plays a significant part in the progression of tumors [8-11]. Also psychological stress intensifies the initiation and the progression of cancer in humans as well as animals [12,13]. It has been noted that stress appears to not only promote the progression of tumors induced chemically [14-17] but causes a reduction in the efficacy of cyclophosphamide, a cytotoxic antitumor drug [18]. Also, rotational stress reduced the efficacy of antitumor drugs which is seen by extent of metastasis, the tumor burden, and survival period in animal studies $[19,20]$.

We have previously shown that pre-exposure to restraint stress markedly increased DMBA induced oxidative stress along with DNA damage in experimental animals [21,22]. Melatonin has been shown to modulate the clastogenicity of DMBA in mammary tumors and other carcinogens by defending cells from DNA damage induced by them [4]. Present study was carried out to see whether: 1. Melatonin is therapeutically effective on topically applied DMBA, and 2. Restraint stress alters the chemoprevention of DMBA induced carcinogenesis by melatonin in terms of antioxidant parameters The parameters considered were superoxide dismutase (SOD) enzyme activity, catalase (CAT) enzyme activity, glutathione reductase (GR) enzyme activity, Glutathione-S-transferase (GST) enzyme activity; malondialdehyde (MDA) and reduced glutathione (GSH) levels. Comet assay was used to determine damage of DNA, and fluorescent spectroscopy sensitively detected any alteration in biochemical status as normal and cancerous tissues fluoresce at different wavelengths [23].

\section{Materials and methods}

\section{Animals}

Fifty Swiss albino young male rats, weight approximately $40 \pm 5 \mathrm{~g}$ were taken for the study and fed a commercial diet procured from Ashirwaad industries, Chandigarh, India. Standard conditions of the temperature, humidity and housing the animals were followed with water given ad libitum. A $12 \mathrm{~h}$ light/dark cycle was maintained. The experimental design was found appropriate by the Animal Ethical Committee of the university (AEC/LFS/2719). The procedures set by national CPCSEA (Committee for the Purpose of Control and Supervision of Experiments on Animals) were promptly followed.

\section{Treatment of animals}

After acclimatizing the animals for a week, they were segregated into five sets, with each set consisting of 10 rats. Animals from group I served as control and was not given any treatment. Animals in group II (DMBA treated) with their backs shaved off two days prior to the commencement of experiment, were treated with $0.5 \%$ DMBA topically, dissolved in sesame oil, two times a week for a total period of 18 weeks. Group III rats were treated with chronic restraint stress (CRS) for the first ten days for a period of three hours each day. This was followed by treatment with DMBA similar to group II. Restraint stress was accomplished by restricting their movements by keeping the animals singly in small body sized cages made of wire attached to wooden boards. Group IV (melatonin DMBA 'Mlt-DMBA' treated) animals were treated as group II except that they were treated with melatonin $(200 \mu \mathrm{l}$ of the solution in acetone with $0.05 \mu \mathrm{g} /$ $\mathrm{ml}$ concentration) thirty minutes before applying DMBA. At the start group V animals (Pre-stress DMBA melatonin treated) were treated with chronic restraint stress very much like the group III animals, then subjected to the same treatment as given to Group IV. The timings of the experiment were designed so that melatonin was given no later than three hours before lights were switched off.

After 18 weeks all the animals were sacrificed blood collection was done along with the samples of liver and skin. These were used for further biochemical analysis.

\section{Processing of cells for comet assay}

\section{Separation of lymphocyte/plasma}

As soon as the animals were sacrificed, the collected heparinized blood was diluted in $\mathrm{Ca}^{++}$and $\mathrm{Mg}^{++}$free PBS solution. Histopaque 1077 was used for the isolation of 
lymphocytes. Cells were suspended in RPMI 1640 and their viability assessed using the trypan blue exclusion test [24]. Heparinized blood was centrifuged (3000 rpm for five minutes) for separation of plasma used for emission and biochemical studies.

\section{Isolation of cells from liver and skin}

A piece of liver lobe was cut and minced thoroughly using a sterilized blade. The minced tissue was later mixed in a solution of HBSS (ice-cold). This was later centrifuged and the cells suspended in RPMI 1640. The same procedure was used for cells isolation of skin tissue.

\section{Analysis of biochemical parameters}

The antioxidant enzyme activity of SOD was estimated by Markland and Marklund method [25]. One enzyme unit of SOD activity was calculated as the amount of protein that caused 50\% inhibition of pyrogallol autoxidation. The SOD activity is expressed as U/mg protein. For CAT [26] one enzyme unit is the amount of enzyme decomposing $1 \mu$ mole of $\mathrm{H}_{2} \mathrm{O}_{2}$ dissipated $\min ^{-1} \mathrm{mg}$ protein ${ }^{-1}$ at $25^{\circ} \mathrm{C}$. GR enzyme activity was calculated using a molar extinction coefficient of $6.22 \times 10^{3} \mathrm{M} / \mathrm{cm}$ and expressed as $\mu \mathrm{mol}$ NADPH oxidized/min/mg protein [27]. GST [28] activity was calculated in the plasma by using molar extinction coefficient value of $9.6 \times 10^{3} \mathrm{M}^{-1} \mathrm{~cm}^{-1}$, using 1-chloro-2, 4-dinitrobenzene (CDNB) as substrate, and the result was expressed as $\mu$ moles CDNB conjugate formed/minute/mg protein. GSH, the non-enzymatic antioxidant was estimated by reaction of GSH with thiol reagent 5,5'-dithiobis-2-nitrobenzoic acid (DTNB)). The yellow color developed was read at $412 \mathrm{~nm}$ [29] and expressed as $\mu \mathrm{mol} \mathrm{GSH} / \mathrm{mg}$ of protein. The lipid peroxidation was estimated by detecting the pink chromogen formed by MDA-TBA complex at $535 \mathrm{~nm}$ [30]. The result was presented as nmoles $\mathrm{MDA} / \mathrm{mg}$ protein using an extinction coefficient of $1.56 \times 105 \mathrm{M}^{-1} \mathrm{~cm}^{-1}$. Protein content was analyzed by the method of Lowry et al. [31].

\section{Fluorescent analysis}

Fluorescent spectral analysis was performed as per Kartheyan et al. [32]. Plasma was collected from heparinized blood by centrifuging at $3000 \mathrm{rpm}$ for $5 \mathrm{~min}$. The pellets were rinsed with $0.9 \%$ saline thrice, and then centrifuged at $3000 \mathrm{rpm}$ to collect the erythrocytes. Erythrocytes were centrifuged at 15,000 rpm for $20 \mathrm{~min}$ and then lysed at $0{ }^{\circ} \mathrm{C}$ for an hour with ice-cold distilled water to collect the erythrocyte membrane in the form of a pastel-yellow pellet. Acetone (Analytical grade $-2 \mathrm{ml}$ ) was added to a fixed amount of plasma, erythrocyte and erythrocyte membrane. After vortexing it was centrifuged at $5000 \mathrm{rpm}$ for ten minutes to obtain a clear supernatant, which was utilized for fluorescent spectral analysis using a spectro-fluorometer by exciting at $400 \mathrm{~nm}$. The emission spectra were noted from 430 to $700 \mathrm{~nm}$. The procedure was conducted in triplicates and the data thus obtained were analyzed statistically.

\section{Analysis of DNA damage}

The procedure of Singh et al. [33] was followed for Comet assay under alkaline conditions which is described by us in details previously [34].

\section{Data analysis}

Data was presented as means \pm SEM and student's $t$ test was employed to analyze the significance. One way ANOVA was used to analyze the variance and $p$ values of $<0.05$ were set as statistically significant. The statistical analyses were performed using GraphPad Prism software.

\section{Results}

\section{Biochemical parameters}

Melatonin showed preventive effect towards DMBA induced modifications of circulatory antioxidant enzymes or biochemical parameters. As depicted in Table 1, $\mathrm{p}$ values for all enzymes (SOD, GST, CAT, GR) showed significant changes. The combined melatonin and DMBA treatment, however, caused an insignificant diminution in the antioxidant enzymes, while prior exposure to stress eliminated the defensive effect of melatonin as represented by $p$ values of the antioxidant enzymes in comparison to the control group. The same outcome was seen on TBARS levels in the blood of treated and control animals which accompanied decreased plasma GSH content (Table 2).

\section{Spectroscopy}

Fluorescent spectra of the control, as well as treated animals are depicted in Figs. 1, 2 and 3 and the emission data in Table 3.

\section{Plasma}

The plasma of controls showed a prominent maximum at $430 \mathrm{~nm}$ after excitation at $400 \mathrm{~nm}$, which then diminished at higher wavelengths as shown in Fig. 1. The plasma of DMBA given group, showed a primary peak at $430 \mathrm{~nm}$, and a secondary peak at $630 \mathrm{~nm}$ with a significantly reduced FI $530 \mathrm{~nm} / 630 \mathrm{~nm}$. The secondary peak intensity was enhanced in prior stress DMBA treated group and FI $530 \mathrm{~nm} / 630 \mathrm{~nm}$ 
Table 1 Circulatory activities of enzymatic antioxidants SOD, Glutathione-S-transferase (GST), CAT and GR after treatment with DMBA alone, DMBA-melatonin, and pre-stress DMBA and prestress DMBA melatonin treatment

\begin{tabular}{|c|c|c|c|c|}
\hline Groups & $\begin{array}{l}\text { SOD } \\
\text { (Units/mg protein) }\end{array}$ & $\begin{array}{l}\text { GST } \\
\text { ( } \mu \text { moles CDNB conjugate } \\
\text { formed/ minute /mg protein) }\end{array}$ & $\begin{array}{l}\text { CAT } \\
\text { (mole of } \mathrm{H}_{2} \mathrm{O}_{2} \text { consumed/ } \\
\text { min/mg protein) }\end{array}$ & $\begin{array}{l}\text { GR } \\
(\mu \mathrm{mol} \mathrm{NADPH} \\
\text { oxidized/min/mg } \\
\text { protein) }\end{array}$ \\
\hline Untreated Control & $5.21 \pm 0.06$ & $2.53 \pm 0.03$ & $29.89 \pm 0.46$ & $20.09 \pm 0.37$ \\
\hline DMBA alone & $1.52 \pm 0.02 *$ & $1.08 \pm 0.02 *$ & $19.18 \pm 0.54 *$ & $8.40 \pm 0.26^{*}$ \\
\hline Pre-stress-DMBA & $0.50 \pm 0.01 * \#$ & $0.32 \pm 0.01 * \#$ & $9.45 \pm 0.53 * * \#$ & $4.78 \pm 0.34 * * \#$ \\
\hline DMBA-Melatonin & $4.05 \pm 0.03 \#$ & $1.82 \pm 0.01 \#$ & $25.76 \pm 0.64 \#$ & $15.96 \pm 0.51 \#$ \\
\hline Prestress-DMBA Melatonin & $2.80 \pm 0.02 * *$ & $1.25 \pm 0.01 * *$ & $14.17 \pm 0.25^{* *}$ & $9.87 \pm 0.35^{* *}$ \\
\hline
\end{tabular}

Data represents mean \pm S.E.M. of 10 animals in each group

$* p<0.01$ significant when compared to control group

${ }^{\#} p<0.05$ significant, when compared to DMBA alone group

$* * p<0.05$ significant when compared to DMBA-Mlt group. SOD values are expressed as Units/mg protein. One unit of enzyme was defined as the amount of enzyme that caused $50 \%$ inhibition of pyrogallol autoxidation

Table 2 Plasma levels of reduced glutathione $(\mathrm{GSH})$ and malondialdehyde (MDA) after treatment with melatonin in DMBA alone and pre-stress DMBA treated animals

\begin{tabular}{lll}
\hline Groups & $\begin{array}{l}\text { Reduced glutathione }(\mu \mathrm{mol} \mathrm{GSH} / \\
\text { mg protein) }\end{array}$ & $\begin{array}{l}\text { Lipid peroxidation (nmoles } \\
\text { MDA formed/mg protein) }\end{array}$ \\
\hline Untreated control & $5.21 \pm 0.06$ & $2.53 \pm 0.03$ \\
DMBA alone & $1.52 \pm 0.02^{*}$ & $1.08 \pm 0.02^{*}$ \\
Prestress-DMBA & $0.50 \pm 0.01^{*} \#$ & $0.32 \pm 0.01 * \#$ \\
DMBA-Melatonin & $4.05 \pm 0.03 \#$ & $1.82 \pm 0.01 \#$ \\
Prestress-DMBA Melatonin & $2.80 \pm 0.02^{* *}$ & $1.25 \pm 0.01^{* *}$ \\
\hline
\end{tabular}

Data represents mean \pm S.E.M. of 10 animals in each group

$* p<0.01$, significant when compared to control

${ }^{\#} p<0.05$, significant when compared to DMBA alone group

$* * p<0.05$, significant when compared to DMBA-Mlt group

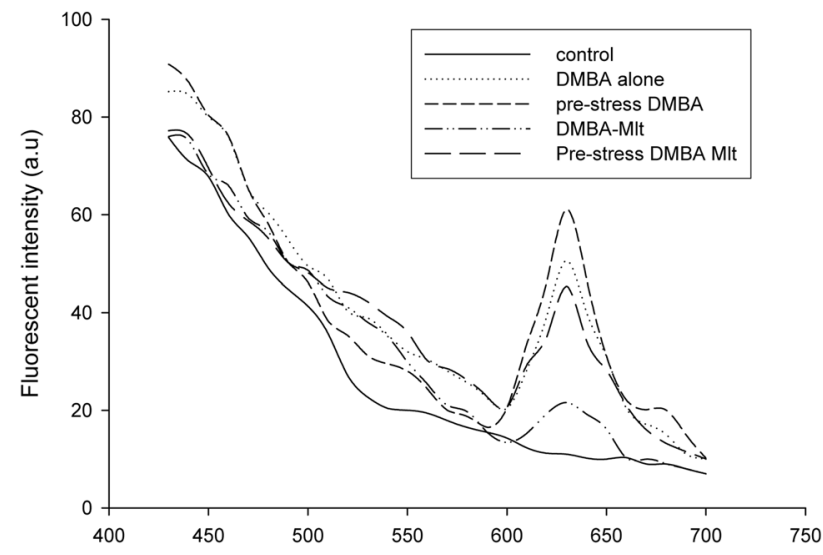

Fig. 1 Emission spectra of plasma of control, DMBA alone, prestress-DMBA, DMBA-melatonin and pre-stress-DMBA melatonin treated samples on excitation at $400 \mathrm{~nm}$

decreased further in comparison to control or DMBA alone treated group. While the DMBA-melatonin treated group showed the secondary peak significantly decreased and

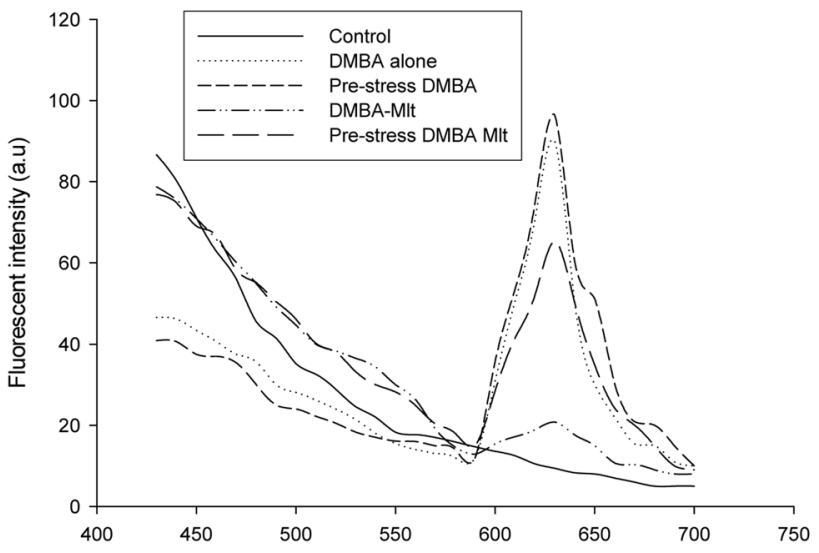

Fig. 2 The emission spectra of erythrocyte samples obtained from control, DMBA alone, pre-stress-DMBA, DMBA-melatonin and prestress-DMBA melatonin treatments after excitation at $400 \mathrm{~nm}$

FI nearly approached the untreated control group values. But, prior restraint stress exposure of animals and then DMBA-Melatonin treatment depicted that the intensity of 


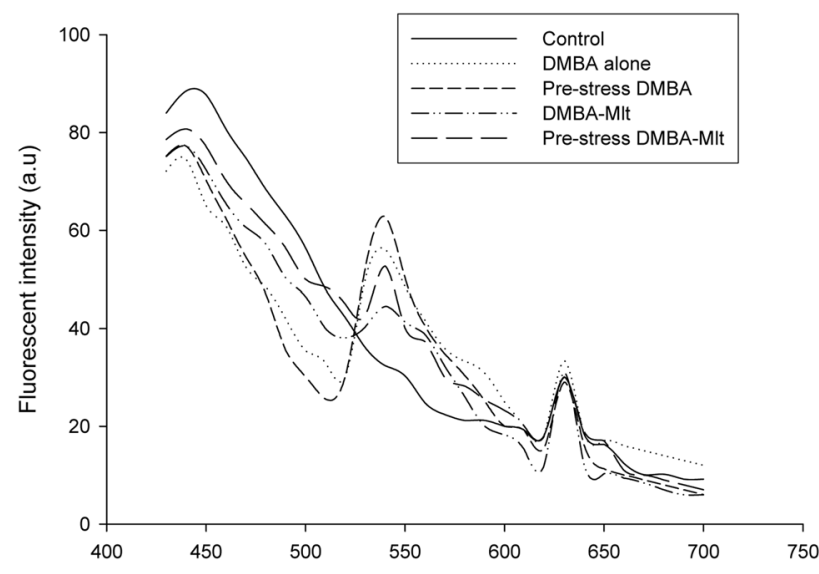

Fig. 3 Erythrocyte membrane emission spectra of control, DMBA alone, pre-stress-DMBA-melatonin and pre-stress-DMBA melatonin treated samples on excitation at $400 \mathrm{~nm}$

secondary peak and FI530nm/630 $\mathrm{nm}$ ratio increased further and was not significantly different or similar to only DMBA treatment.

\section{Erythrocytes}

Fluorescent spectra of the red blood cells samples of control and treated animals are shown in Fig. 2. This was found to be comparable to the spectra using plasma samples. However, these erythrocyte samples exhibited more fluorescence when compared to plasma in terms of the intensity, as observed in Table 3 (FI $530 \mathrm{~nm} / 630 \mathrm{~nm}$ ).

\section{Erythrocyte membrane}

Maximum intensity of the erythrocyte membrane of both control as well as treated groups was observed at $440 \mathrm{~nm}$ followed by another at $630 \mathrm{~nm}$ (Fig. 3). A secondary peak was also observed at $540 \mathrm{~nm}$ by the treated groups as observed in Fig. 3c. The treated groups exhibited a higher FI as compared to controls, unlike its reduction in the plasma and erythrocytes. The pre-stress DMBA group exhibited maximum rise as compared to all remaining groups. As compared to the controls, FI of DMBA-melatonin was increased insignificantly, but that of pre-stress DMBA-melatonin was increased significantly as compared to control, but insignificantly in comparison to DMBA alone.

\section{Comet assay}

Determined as increased tail movement, DNA damage was significant in the lymphocytes, liver and skin cells of the DMBA treated animals in comparison to controls (Fig $4 \mathrm{a}-\mathrm{c}$ respectively and comet tail length in skin cells Fig. 5). The Pre-stress DMBA group indicated a further enhancement in tail length meaning more DNA damage or maximum, in comparison to rest of the groups $(p<0.001)$.

The treatment with melatonin and DMBA (group IV), resulted in significant $(p<0.05)$ increase in the tail length from control group, though was reduced significantly $(p<0.01)$ as compared to DMBA alone treated animals, showing a protective influence of melatonin against DMBA induced DNA damage. Though, exposure to restraint stress before treatment with DMBA-Melatonin, increased the DNA damage further significantly $(p<0.01)$ in comparison to Mlt + DMBA treated group, but was not significantly different from only DMBA treatment.

The highest level of DNA damage was seen in the skin cells as depicted by tail lengths for DMBA alone or prestress DMBA treatment followed by liver and peripheral lymphocytes (Fig. 4a-c and comet tail length in skin cells Fig. 5). The DNA damage results from highest to lowest as per the tissue studied can be summarized as below:

Skin cells $>$ liver cells $>$ peripheral lymphocytes.
Table 3 Emission characteristics of Plasma, erythrocyte and erythrocyte membrane of control and experimental groups of rats during fluorescent spectral analysis excited at $400 \mathrm{~nm}$

\begin{tabular}{llll}
\hline Groups & $\begin{array}{l}\text { (FI 530/630) } \\
\text { Plasma }\end{array}$ & $\begin{array}{l}\text { (FI 530/630) } \\
\text { Erythrocyte }\end{array}$ & $\begin{array}{l}\text { (FI 530/630) } \\
\text { Erythrocyte membrane }\end{array}$ \\
\hline Untreated Control & $2.02 \pm 0.14$ & $2.61 \pm 0.21$ & $1.20 \pm 0.16$ \\
DMBA alone & $0.70 \pm 0.07^{*}$ & $0.24 \pm 0.06^{*}$ & $1.51 \pm 0.008^{*}$ \\
Prestress-DMBA & $0.51 \pm 0.03^{* \#}$ & $0.19 \pm 0.07^{* \#}$ & $1.82 \pm 0.05^{* \#}$ \\
DMBA-Melatonin & $1.76 \pm 0.04 \#$ & $1.75 \pm 0.12 \#$ & $1.30 \pm 0.10 \#$ \\
Prestress DMBA-Melatonin & $0.92 \pm 0.012^{* *}$ & $0.5 \pm 0.05^{* *}$ & $1.42 \pm 0.03^{* *}$ \\
\hline
\end{tabular}

Data represents mean \pm S.E.M. of 10 animals in each group

${ }^{*} p<0.01$, significant when compared to control

${ }^{\#} p<0.05$, significant when compared to DMBA alone group

$* * p<0.05$, significant when compared to DMBA-Mlt group

${ }^{\#} p<0.05$, significant when compared to DMBA-Res group 

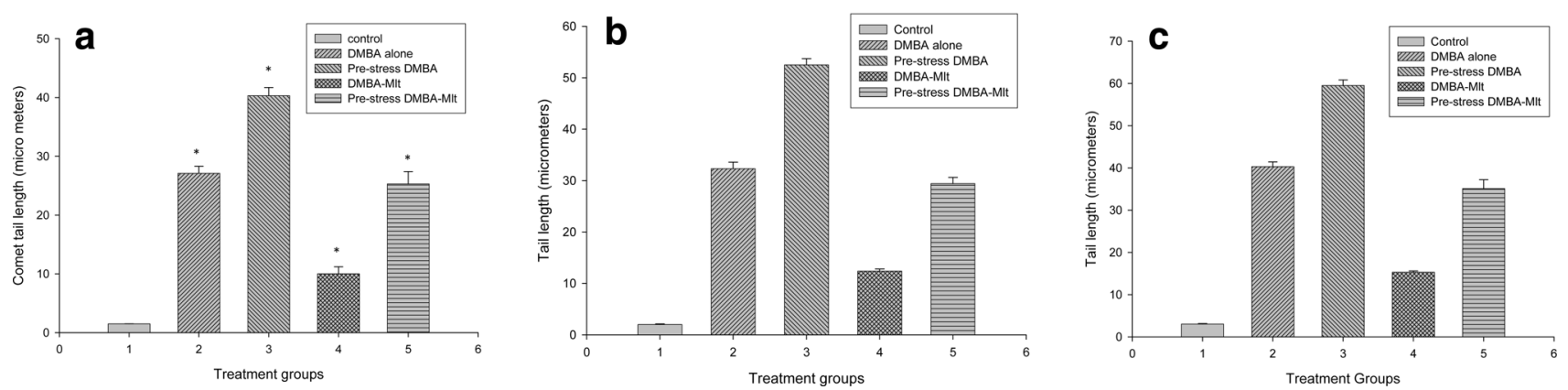

Fig. 4 a-c DNA damaging effect of DMBA alone, pre-stress-DMBA, DMBA-melatonin and pre-stress-DMBA melatonin exposure, on the peripheral lymphocytes (a), liver (b) and skin cells (c) of rats. The rats were exposed to chronic restraint stress $(3 \mathrm{~h} /$ day) for 10 days, or topically treated with $0.5 \%$ DMBA in sesame oil (twice a week) for
18 days either alone or after exposure to stress, DMBA-melatonin and pre-CRS-DMBA-melatonin as described in Sect. 2. Untreated controls were also run simultaneously. Values reported are as mean \pm S.E.M. of ten animals in each group
Fig. 5 Single cell gel electrophoresis of rat skin cells showing Comets (100x) after treatments with $0.5 \%$ DMBA, pre-stress and melatonin treatments as described in Sect. 2; a Untreated control, b DMBA treated, $\mathbf{c}$ Pre-stress DMBA, d DMBA-melatonin, e pre-stress DMBA melatonin (a) Untreated control

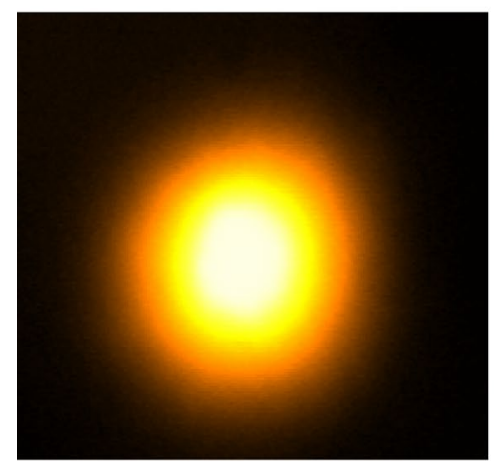

(c) Pre-stress DMBA

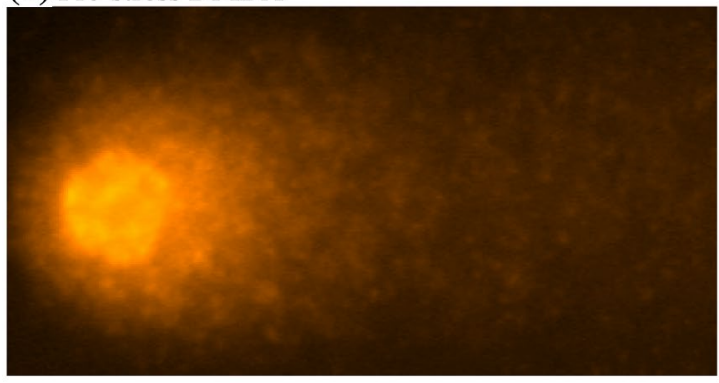

(d) DMBA-melatonin

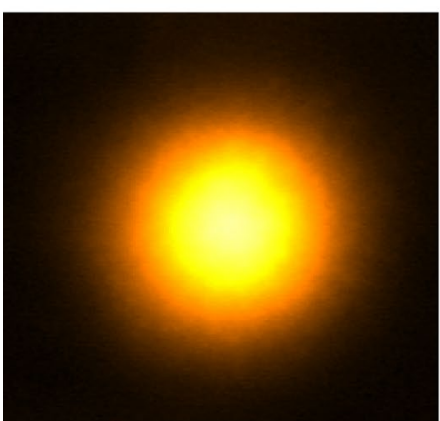

(e) Pre-stress DMBA-melatonin

(b) DMBA alone
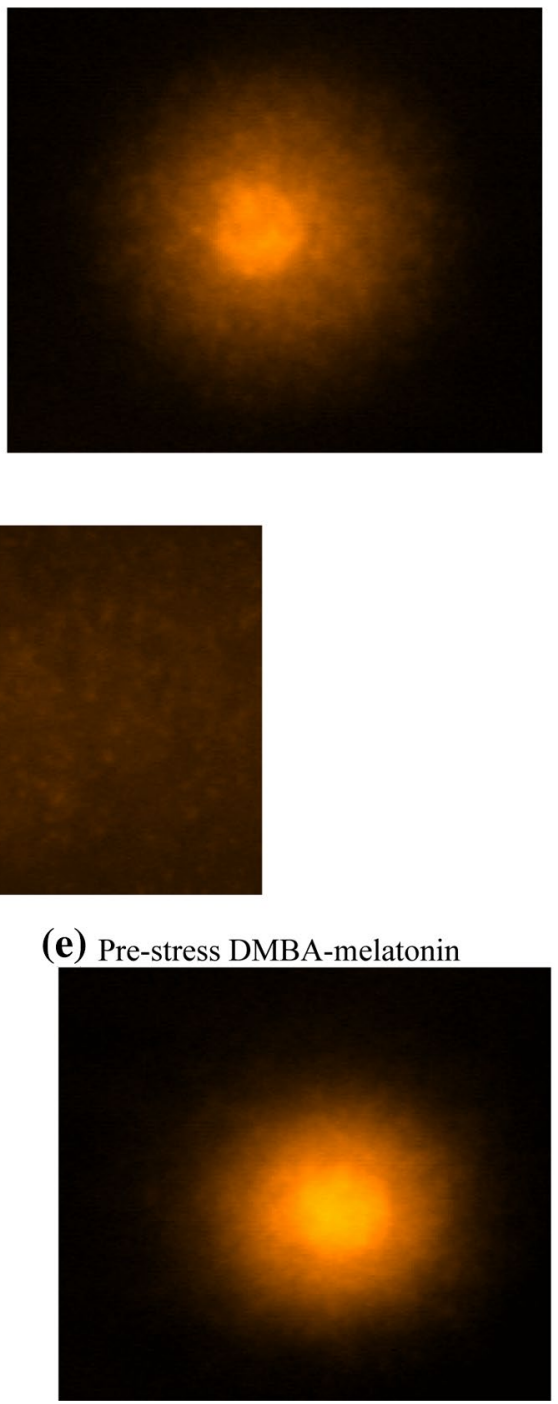


\section{Discussion}

For the past few years the part played by the pineal gland through melatonin in the development and progression of tumor has been under extensive investigation. In cancer patients the pineal function is found decreased along with alteration in the morphological signs with a decrease and disturbance in the secretion pattern of melatonin [21]. Further, in pinealectomized animals the growth of a variety of tumors is accelerated. The protective influence of melatonin is well-known in relation to DMBA promoted mammary cancers [35-38] and skin carcinogenesis induced by either DMBA or other carcinogens [39]. The present study evaluated both the efficacy of melatonin on DMBA induced carcinogenesis and its modulation by restraint stress. DMBA causes DNAdestruction in mammalian cells through free radical generation and activation of lipid peroxidation [40]. Our previous studies have shown that restraint stress per se was not effective in causing any substantial DNAdamage but it increased the DNAdestructive potential of DMBA [22] as is shown in the present study too from compounded DNAdamage observed in group III animals as compared to all other groups. This is because CRS exacerbated oxidative stress and peroxidation of lipid in these animals $[21,22]$.

The peroxyl radicals generated during lipid peroxidation were found very efficiently neutralized by melatonin [41] it could reduce the damaging potential of DMBA in all the three experimental cells studied in group IV animals (DMBA-Mlt). Because of its dual lipophilic and hydrophilic properties, melatonin acts in all cells and subcellular compartments too. It neutralizes the free radicals directly, and also stimulates the activity of GPx enzyme, thus diminishing the oxidative damage [41, 42]. Through its anti-oxidative role melatonin protects the macromolecules DNA, protein and lipids from oxidative destruction due to carcinogen insult. However, pre-exposure to restraint stress decreased the efficacy of melatonin as depicted by increased DNA damage in these animals when compared to group IV (Mlt-DMBA) animals. This may be due to the fact that melatonin when applied prior to DMBA in group IV animals was capable of countering any damage induced by DMBA, but it failed to protect cells due to already existing oxidative burden induced by restraint stress (group V). Therefore, the anti-oxidative properties of melatonin were effective in protecting cells against DMBA induced damage but were found to be less effective under increased oxidative burden due to restraint stress and DMBA in combination.

Under pathological conditions the biochemical changes are different from the normal tissues in terms of the native chromophores/fluorophores. Thus any change in the pathological status can be effectively depicted with the help of sensitive fluorescent spectroscopy [43]. During the proliferation tumor angiogenesis takes place which is well-known [44] thus the transference of these fluorophores is possible which can be sensed in the red blood cells. The local environment can be characterized by the production of natural intrinsic fluorophores namely porphyrins NAD (P)H and flavins which exhibit a characteristic spectra at 470,520 and $630 \mathrm{~nm}$ respectively [34]. The intensity ratio of fluorescence at $530 \mathrm{~nm}$ and $630 \mathrm{~nm}$ (FI530nm/630 nm), seems specific for a certain tissue but any variation in the fluorophores ratio, portrays an altered local as well as native environment. A prominent peak at $630 \mathrm{~nm}$ (Figs. 1 and 2) was shown by the plasma and erythrocytes of DMBA treated animals, while the erythrocyte membrane revealed a peak at $540 \mathrm{~nm}$ (Fig. 3) this could be explained as to either an alteration in the local environment or to the creation of new fluorophores as a result of the carcinogen. In the plasma and erythrocyte of pre-exposed restraint stress a significant increase in the $\mathrm{FI}$ at $630 \mathrm{~nm}$ and $520 \mathrm{~nm}$ and lessened FI530 nm/630 nm ratio was observed, while there was an increase in the erythrocyte membrane fluorescent intensity in comparison to DMBA alone treated group. The enhanced oxidative stress in pre-exposed CRS-DMBA group may be the cause of amplified increase of fluorophores through an unknown mechanism. The topical melatonin treatment decreased the peaks at $630 \mathrm{~nm}$ and $540 \mathrm{~nm}$ with a significant alteration of the FI530 nm/630 nm in comparison to DMBA alone group comparable to that of control group. Melatonin might have directly interacted with the activation process metabolically, or subdued the cytochrome P450 reliant monooxygenase enzyme system, or may be via its indirect action on the stimulation of glutathione and glutathione peroxidase enzyme [6], thus causing a reduction in the oxidative damage induced by the carcinogen. Effectiveness of melatonin is reduced on DMBA induced damage in the group of animals which were pre-exposed to restraint stress. Thus possibly melatonin through its indirect action is involved in combatting restraint stress induced oxidative stress and enhanced the DMBA induced in vivo oxidative status [22]. Based on melatonin's high safety profile, permeability through vessels, anxiety reduction and as a sedative improving the sleep quality, which otherwise is lacking in cancer patients due to the stress of the disease itself, can be suggested as a therapeutic drug. Moreover, because of its anti-inflammatory and anti-oxidative properties, melatonin is recently suggested as an adjuvant therapeutic agent in Covid-19 [45].

The results of both the fluorescence spectroscopy and of Comet assay are found highly comparable. Thus, it can be concluded that melatonin acting directly as an antioxidant, and indirectly via receptor mediated increase of antioxidant 
enzyme activities is highly effective against DMBA induced damage and chronic restraint stress, with enhanced DMBA engendered destruction, restraint stress reversed or repressed the chemo-preventive efficacy of melatonin. Thus, stress control should be deliberated as a serious factor during cancer chemo-preventive/therapy trials and further studies should be aimed to see effect of stress reduction during chemotherapy.

\section{Conclusion}

The chemo-preventive studies with the antioxidants melatonin were found effective against DMBA induced carcinogenesis as depicted by alterations in the antioxidant status, DNA damage and fluorescent studies. Nevertheless, prior CRS exposure decreased the chemo-preventive/antioxidant ability of melatonin, thereby playing a crucial role in cancer development and chemoprevention in cancer. Thus, stress should be managed during cancer chemo-preventive/therapeutic interventions in sleep deprived cancer patients with reduced production of melatonin and diminished oxidative status.

Acknowledgements All authors thank the UGC-DRS as well as DST(FIST), in providing facilities at the laboratory. Also thanks to the Indian Council of Medical Research (New Delhi) for providing financial assistance in the form of scholarship to the author (IM). Also we thank Qassim University.

Author contributions IM and NB have contributed towards the conception, design, data acquisition (SF, ASA), data analysis and interpretation (SF). IM, SF, NB, ASA, ASAl and SAK drafted and revised the manuscript critically; all the authors finally approved for publication of the manuscript in its present form.

Funding The work is not supported by any grant.

Availability of data All the data included in the study are given in the manuscript.

\section{Compliance with ethical standards}

Conflict of interest All authors declare no conflicting interest.

Ethical approval The study was approved by the Animal Ethical Committee of the university and followed the protocol of national CPCSEA (Committee for the Purpose of Control and Supervision of Experiments on Animals).

\section{References}

1. Jemal A, Thomas A, Murray T, Thun MJ. Cancer statistics. Cancer J Clin. 2002;52:23-47.

2. Lahiri M, Mukhtar H, Aggarwal R. Reactive intermediates and skin cancer. In: Kitchin KT, editor. Carcinogenicity: testing, predicting and interpreting chemical effects. New York: Marcel Dekker; 1999. p. 679-717.

3. Ames BN, Gold LS, Willett WC. The causes and prevention of cancer. Proc Natl Acad Sci USA. 1995;92:5258-65.

4. Musatov SA, Anisimov VN, Andre V, Vigrens C, Godard T, Gauduchon P, Sichel F. Modulatory effects of melatonin on genotoxic response of reference mutagens in the Ames test and the comet assay. Mut Res. 1998;417:75-84.

5. Ya L, Sha L, Yue Z, Xiao M, Jiao-Jiao Z, Dong-Ping X, HuaBin L. Melatonin for the prevention and treatment of cancer. Oncotarget. 2017;8(24):39896-921.

6. Karbownik M, Lewinski A, Reiter RJ. Anticarcinogenic actions of melatonin which involve antioxidant processes: comparison with other antioxidants. Int J Biochem Cell Biol. 2001;33:735-53.

7. Anisimov VN, Popovich IG, Zabezhinski A, Anisimov SV, Vesnushkin GM, Vinogradova IA. Melatonin as antioxidant, geroprotector and anticarcinogenic. Biochim Biophy Acta. 2006;1757:573-89.

8. Torres RL, Torres ILS, Gamaro GD, Fontella FU, Silveira PP, Moriera JSR, et al. Lipid peroxidation and total radical trapping potential of the lungs of rats submitted to chronic and subchronic stress. Braz J Med Biol Res. 2004;37:185-92.

9. Cooper CL, Faragher EB. Psychological stress and breast cancer. The inter-relationship between stress events, coping strategies and personality. Psychol Med. 1993;23:653-62.

10. Greer S, Moorey S, Brauch JD, Watson M, Robertson BM, Mason A, Rowden L, Law MG, Bliss JM. Adjuvant psychological therapy for clinically referred patients. Br J Cancer. 1991;63:257-60.

11. Jensen AB. Psychological factors in breast cancer and their possible impact upon prognosis. Cancer Treat Rev. 1999;18:191-21010.

12. Temoshok L. Personality, coping style, emotion and cancer: Towards an integrative model. Cancer Surv. 1987;6:45-567.

13. Sali A. Psychoneuroimmunology. Fact or fiction? Aust Fam Phys. 1997;26(11):1291-4

14. Bergsma J. Illness, the mind and the body: cancer and immunology: an introduction. Theor Med. 1994;15(4):337-47.

15. Amkraut A, Solomon GF. Stress and murine sarcoma virus (moloney)-induced tumors. Cancer Res. 1972;32:1428-33.

16. Justice A. Review of the effects of stress on cancer in laboratory animals: importance of time of stress application and type of tumor. Psycholl Bull. 1985;98:108-38.

17. Pradhan SN, Ray P. Effects of stress on growth of trasplanted and 7,12-dimethylbenz (a) anthracene induced tumors and their modification by psychotropic drugs. J Natl Cancer Inst. 1974;53:1241-5.

18. Steplewski Z, Vogel WH, Ehya H, Poropatich C, Mc Donald SJ. Effects of restraint stress on inoculated tumor growth and immune response in rats. Cancer Res. 1985;45:5128-33.

19. Zorzet S, Perissan L, Rapozzi V, Giraldi T. Restraint stress reduces the antitumor efficacy of cyclophosphamide in tumor-bearing mice. Brain Behav Immun. 1998;12:23-33.

20. Giraldi T, Perissan L, Zorzet S, Rapozzi V. Metastasis and neuroendocrine system in stressed mice. Ann NY Acad Sci. 1992;650:297-301.

21. Giraldi T, Perissan L, Zorzet S, Rapozzi V. Stress, melatonin and tumor progression in mice. Ann NY Acad Sci. 1994;719:526-36.

22. Muqbil I, Banu N. Enhancement of pro oxidant effect of 7,12Dimethylbenz (a) anthracene (DMBA) in rats by pre exposure to restraint stress. Cancer Lett. 2006;240:213-20.

23. Zonios G. Spectral pathology. Ann NY Acad Sci. 1998;838:108-15.

24. Pool-Zobel BL, Guigas C, Klein RG, Neudecker CH, Renner HW, Schnezer P. Assessment of genotoxic effect by lindane. Food Chem Toxicol. 1993;31:271-83. 
25. Markland S, Markland G. The involvement of the superoxide anion radical in the auto oxidation of Pyrogallol and a convenient assay for superoxide dismutase. Eur J Biochem. 1974;47:469-74.

26. Claiborne A. Catalase activity. In: Green Wald RA, editor. CRC handbook of methods for oxygen radical research. Boca Raton: CRC Press; 1985. p. 283-284.

27. Carlberg I, Mannervik B. Purification and characterization of the flavoenzyme glutathione reductase from rat liver. J Biol Chem. 1975;250:5475-80.

28. Habig W, Pabst MJ, Jacoby WH. Glutathione-s-transferases: the first step in mercapturic acid formation. J Biol Chem. 1994;249:7130-9.

29. Jollow DJ, Mitchell JR, Zampaglione N, Gillete JR. Bromobenzene induced liver necrosis: protective role of glutathione and evidence for 3,4, bromobenzene oxide as the hepatotoxic intermediate. Pharmacology. 1974;11:151-69.

30. Buege JA. Aust SD Microsomal lipid peroxidation. Methods Enzymol. 1978;52:302-10.

31. Lowry OH, Rosenberg NJ, Farr AL, Randall RJ. Protein measurement with folin phenol reagent. J Biol Chem. 2006;193:265-75.

32. Karthikeyan K, Masilamani V, Govindasamy S. Spectrofluorimetric detection of DMBA-induced mouse skin carcinoma. Pathol Oncol Res. 1999;5:46-8.

33. Singh NP, McCoy MT, Tice RR, Schneider EL. A simple technique for quantitation of low levels of DNA damage in individual cells. Exp Cell Res. 1998;175:184-91.

34. Muqbil I, Azmi AS, Banu N. Prior exposure to restraint stress enhances 7, 12- Dimethylbenz (a) anthracene (DMBA) induced DNA damage in rats. FEBS Lett. 2006;580:3995-9.

35. Vijayalaxmi CR, Thomas RJ, Herman TS. Melatonin: from basic research to cancer treatment clinic. J Clin Oncol. 2002;20:2575-601.

36. Cutando A, López-valverde A, Arias-santiago S, De vicente J, Gómez De Diego R. Role of melatonin in cancer treatment. Anticancer Res. 2012;32:2747-54.
37. Li Y, Li S, Zhou Y, Meng X, Zhang J-J, Dong-Ping Xu, Li H-B. Melatonin for the prevention and treatment of cancer. Oncotarget. 2017;8(24):39896-921.

38. Kumar CA, Das UN. Effect of melatonin on two stage carcinogenesis in Swiss mice. Med Sci Monit. 2000;6(3):471-5.

39. Frenkel K, Wei L, Wei H. 7,12-dimethylbenz (a) anthracene induces oxidative DNA modification in vivo. Free Rad Biol Med. 1995;19:373-80.

40. Lesnikov VA, Pierpoali W. Pineal cross-transplantation (old to young and vice-versa) as evidence for an endogenous "aging clock". Ann NY Acad Sci. 1994;719:461-73.

41. Wang Y, Wang P, Zheng X, Du X. Therapeutic strategies of melatonin in cancer patients: a systematic review and meta-analysis. Onco Targets Ther. 2018;11:7895-908.

42. Reiter RJ. The pineal gland and melatonin relation to aging: a summary of the theories and of the data. Exp Gerontol. 1995;30:199-21212.

43. Alfano RR, Tang GC, Pradhan A, Law W, Choy DSJ, Opher E. Fluorescent spectra from cancerous and normal human breast and lung tissues. IEEEQE. 1987;23:1086-118.

44. Fox SB, Gatter KC, Harris AL. Tumor angiogenesis. J Pathol. 1996;16:232-7.

45. Zhanga R, Wanga X, Nia L, Dia X, Maa B, Niua S, Liua C. Reiterb RJ COVID-19: melatonin as a potential adjuvant treatment. Life Sci. 2020;250:117583-9.

Publisher's Note Springer Nature remains neutral with regard to jurisdictional claims in published maps and institutional affiliations. 